\title{
Steady-State Simulation of the Counter Current Liquid-Liquid Ex-Traction: Trimetozine Synthesis as a Case Study
}

Zied Hosni, Ian Houson, Brahim Benyahia, Alastair Florence

Submitted date: 17/08/2019 - Posted date: 19/08/2019

Licence: CC BY-NC-ND 4.0

Citation information: Hosni, Zied; Houson, lan; Benyahia, Brahim; Florence, Alastair (2019): Steady-State Simulation of the Counter Current Liquid-Liquid Ex-Traction: Trimetozine Synthesis as a Case Study. ChemRxiv. Preprint.

The countercurrent liquid-liquid extraction is a crucial step in industrial process to purify and extract a compound of inter-ests for its impurities. This step requires generally challenging and time-consuming optimisation of numerous factors that affect the overall yield of extraction and the energy needed. The simulation of this process has been investigated in this pa-per using a Non-Random Two Liquid model implemented as a thermodynamic method in Aspen. The outcome of this model enables the evaluation of the partition coefficients of the different analytes of a mixtures at the different compart-ments of extraction platform. In addition, this steady-state model allows a more straightforward optimisation of the factors that drive the performance of extraction.

File list (2)

Liq-liq extraction in Aspen v2.docx (4.59 MiB) view on ChemRxiv • download file 


\title{
Steady-state simulation of the counter current liquid-liquid extraction: Trimetozine synthesis as a case study
}

\author{
Zied Hosni, ${ }^{a}$ Ian Houson, ${ }^{\mathrm{a}}$ Brahim BenYahia, ${ }^{\mathrm{b}}$ Alastair Florence ${ }^{\mathrm{a}}$ \\ ${ }^{a}$ EPSRC Centre for Innovative Manufacturing in Continuous Manufacturing and Crystallisation, \\ Department of Chemical and Process Engineering, University of Strathclyde, James Weir Building, \\ 75 Montrose Street, Glasgow G1 1XJ, United Kingdom \\ ${ }^{b}$ Loughborough University, Loughborough, United Kingdom
}

\begin{abstract}
KEYWORDS Liquid-liquid extraction, impurities rejection, Aspen simulation, Automation, feedback control
\end{abstract}

\begin{abstract}
The countercurrent liquid-liquid extraction is a crucial step in industrial process to purify and extract a compound of interests for its impurities. This step requires generally challenging and timeconsuming optimisation of numerous factors that affect the overall yield of extraction and the energy needed. The simulation of this process has been investigated in this paper using a Non-Random Two Liquid model implemented as a thermodynamic method in Aspen. The outcome of this model enables the evaluation of the partition coefficients of the different analytes of a mixtures at the different compartments of extraction platform. In addition, this steady-state model allows a more straightforward optimisation of the factors that drive the performance of extraction.
\end{abstract}

\section{Introduction}

Liquid-liquid extraction is a major task in the chemical engineering field. ${ }^{1}$ It requires usually a typical ternary system process: solute, diluent, and extractant. Solute, which is dissolved in diluent, is extracted from the diluent and dissolved into another solvent, the extractant. ${ }^{2}$ It separates chemicals from one solution to another based on the different solubility of the solute in two solvents. It is considered as a pre-treatment in many analytical applications in order to pre-concentration and/or separation of multiple analytes such as ultra-trace metal and metalloid species, ${ }^{3}$ phenolic compounds, ${ }^{4,5}$ surfactants, ${ }^{6}$ pharmaceuticals, ${ }^{7}$ etc. Despite its importance, LLE is a limiting step to achieve the desired analytical efficiency. It increases the selectivity by concentrating the analyte from a large sample volume and promote its isolation from matrix-interfering species. This traditional technique still suffers from several disadvantages because it is labour-intensive and time-consuming, which leads to a significant need for large amount of chemicals that can be harmful, expensive and environmentally hazardous and can form eventually emulsions difficult to separate under certain conditions. ${ }^{8}$ The distribution $\mathrm{D}$ of the solute to be extracted among the extracting solvent and the diluent can be described as follows:

$$
D=\frac{S_{e}}{S_{d}}
$$

where $\mathrm{S}_{\mathrm{e}}$ : solute concentration in extractant $(\mathrm{mol} / \mathrm{L})$, $\mathrm{S}_{\mathrm{d}}$ : solute concentration in diluent $(\mathrm{mol} / \mathrm{L})$.

In the Anticó group, Supported Liquid Membrane (SLM) was used to investigate the transport of arsenic species. They built a thermodynamic model that corresponds to the extraction for both $\mathrm{As}(\mathrm{V})$ and As(III) species by employing data generated from the variation of the conditions that affect the extraction such as the organic solvents and $\mathrm{pH}$ of the aqueous phase. The SLM enabled the separation of $\mathrm{As}(\mathrm{V})$ and $\mathrm{As}(\mathrm{III})$ species based on their different kinetic behaviors. Taking into account the good results obtained in liquid-liquid experiments, a Supported Liquid Membrane (SLM) system was developed based on the best separation conditions. ${ }^{9}$

In order to assess molecules lipophilicity, Alimuddin and co-workers determined the octanol-water distribution coefficient $\log \mathrm{D}$ at $\mathrm{pH} 7.4$ for 26 compounds in an automated microfluidic liquidliquid extraction and compared to the results obtained from shake-flask methods. Excellent correlation between the values obtained via both methods was achieved $\left(R^{2}=0.994\right)$. The authors claimed that this technique based on a PTFE membrane extraction is amenable to automation, enabling high-throughput determination of large compound collections. ${ }^{10}$

Artificial Neural Networks were applied to build a model that translates the physicochemical 
behaviour of a pulsed liquid-liquid extraction column. A pulsed liquid-liquid extraction column for the separation of oxalic acid from aqueous solutions using a mixture of tributylphosphate and dodecane as a selective solvent were employed. The training of the Neural Network was carried out offline with the utilisation of the cross-validation in order to achieve a better system representation of noisy data. 6000 different patterns of inputsoutputs were employed for the training and 2992 other patterns were used as a test dataset. The inputs of the algorithm represented the past and the present collected data $(\mathrm{pH}$, conductivity, the concentration) and the outputs represented the future estimated measured $\mathrm{pH}$ and conductivity only. ${ }^{11}$

Binous implemented in Mathematica ${ }^{\circledR}$ a new approach to solve liquid-liquid extraction problems. He considered a ternary mixture of ethanol-water and benzene at $25 \circ \mathrm{C}$ and he employed the software to solve the system of the nonlinear algebraic equations that represent the equilibrium relation between the two liquid phases. He studied also the separation of acetic acid from water using isopropyl ether in singlefeed counter current extractor and two feed extraction columns. In addition, he used the Hunter-Nash method to determine the number of equilibrium stages needed to achieve a particular raffinate specifications. Finally, the McCabe-Thiele diagram was used to compare the previously obtained results. ${ }^{12}$

In the Rajagopalan group, different thermodynamic models were used for the recovery of 2,3-Butanediol (BDO) from fermentation by liquid-liquid extraction. Experimental results of the distribution coefficients $\left(K_{d}\right)$ were compared with the data generated from two theoretical models: Conductor-like Screening Model-Real Solvents (COSMO-RS) and Universal Functional group Activity Coefficient model (UNIFAC-LL). These models permitted to calculate the activity coefficients $\left(\gamma^{\infty}\right)$ of BDO in various solvents. The authors claimed that both models provided qualitative trends of the prediction and the ranking of the solvents according to the experimental references. Among the two quantum-based thermodynamic models, UNIFAC$\mathrm{LL}^{13}$ outperformed the COSMO-RS ${ }^{14}$. It was also highlighted that the integration of the updated parameters from the UNIFAC model in the UNIFACLL calculated provided better results, much closer to the experimental values. The $\left(K_{d}\right)$ values were also calculated in Aspen Plus software. ${ }^{15}$

Thermodynamic-based modelling was also investigated to predict the liquid-liquid equilibria of the (aromatic + aliphatic + ionic liquid) ternary systems. COSMO-SAC is a variant of the COSMORS model and can predict thermodynamic equilibria without any group contribution parameters or experimental data. Only quantum chemical calculations are required, followed by the application of a thermodynamic model. It can also handle variation in concentration and temperature. ${ }^{16}$

Maurer designed a model of the liquid-liquid equilibrium for the recovery of carboxylic acids from aqueous solutions. The separation is driven by the affinity to the organic phase of the weak complex formed between a carboxylic acid and an amine. The author chose a framework based on the equilibrium between citric acid tri, $\mathrm{n}$ octylamine and toluene. The model was constituted of a chemical (the chemical reaction equilibrium) and a physical (the excess Gibbs energy) contribution. In addition, the model allowed the evaluation of the influence of strong electrolyte (salts) on the phase equilibrium. ${ }^{17}$

The purification of an organic molecule from its by-products within the crude of the synthesis is a crucial step before the crystallisation process because the presence of impurities has a crucial impact on the polymorphism of the solid state. The Schotten-Baumann synthesis was investigated heavily as it is providing the amide function from an amine and acid chloride. ${ }^{18}$ This reaction has the particularity to use two immiscible solvent, usually water as the aqueous phase and a polar non-protic organic solvent as the organic phase. The utilisation of the aqueous phase assists the elimination of the acid that is produced in the organic phase. The addition of base such as the sodium Carbonate inhibits also the protonation of the amine by the generated acid and prevents the reduction of the nucleophilicity of the nitrogen in the amine function. The Trimetozine synthesis is a popular example of this reaction as illustrated in Graph $1 .{ }^{19}$

Graph 1. Synthesis of Trimetozine in Me-THF in presence of sodium carbonate.

This commercialised sedative is produced in the presence of three main impurities: unreacted morpholine and trimethoxybenzoyl chloride, and the hydrolysis of the acid chloride giving the trimethoxybenzoic acid. In the present paper, we applied different thermodynamic models implemented in Aspen to simulate the partition of the Trimetozine and its corresponding impurities between the organic and the aqueous phase. We optimised the parameters of three different models: the Non-Random-Two Liquid model, ${ }^{20}$ the UNIversal QUAsiChemical (UNIQUAC) ${ }^{21}$ and the UNIQUAC Functional-group Activity Coefficients $\left(\right.$ UNIFAC) ${ }^{22}$ models. These three models were exploited to drive a global optimisation in order to find the optimum process conditions to achieve the highest yield of Trimetozine extraction at the 
desired purity level using a simulated three-stages countercurrent liquid-liquid extraction.

\section{Experiments}

\subsection{Materials and reagents}

The chemicals employed for the synthesis of trimetozine were obtained from Sigma Aldrich (UK). Morpholine was provided by Santa Cruz (US) and the trimethoxybenzoic acid was purchased from Alfa Aeser (UK). Sodium carbonate and butanol were supplied by VWR (UK). HPLC grade acetonitrile, water, methanol were provided by VWR (UK). $\mathrm{D}_{2} \mathrm{O}$ and deuterated chloroform were purchased from Sigma-Aldrich (UK).

\subsection{Trimetozine synthesis}

To a mixture of morpholine $(87.1 \mathrm{mg}, 1 \mathrm{mmol})$ dissolved Me-THF ( $25 \mathrm{~mL}$ ) was added a mixture of sodium carbonate $(48.1 \mathrm{mg}, 2 \mathrm{mmol})$, and the resultant mixture was stirred at room temperature for $15 \mathrm{~min}$ and then trimethoxybenzoyl chloride (230.6 mg, $1 \mathrm{mmol}$ ) was added. The mixture was stirred for $48 \mathrm{~h}$. On completion, the solid was filtered with a sintered glass funnel. The filtrate was evaporated on a rotary evaporator, the residue was dried on a two-stage pump (high vacuum) and the resultant product was recrystallized and dried in a desiccator, while the liquid products were purified by vacuum distillation. ${ }^{23,24}{ }^{1} \mathrm{H}$ NMR (300 MHz, $\mathrm{CDCl}_{3}$ ) $\delta 6.61$ (s, $2 \mathrm{H}, \mathrm{Ar}-\mathrm{H}), 3.86(\mathrm{~s}, 6 \mathrm{H}, 2 \times \mathrm{OCH} 3), 3.85(\mathrm{~s}, 3 \mathrm{H}$, $\mathrm{OCH} 3), 3.69\left(\mathrm{br}, \mathrm{s}, 8 \mathrm{H}, 4 \times \mathrm{CH}_{2}\right)$.

\subsubsection{Nuclear spectroscopy (NMR) \\ resonance}

${ }^{1} \mathrm{H}$ and ${ }^{13} \mathrm{C}$ NMR experiments were performed on a Bruker $400 \mathrm{MHz}$ NMR spectrometer (Bruker, Falladon, Switzerland) using deuterated chloroform $\left(\mathrm{CDCl}_{3}\right)$ as a solvent and tetramethylsilane (TMS) as an internal standard. The ${ }^{1} \mathrm{H}$ chemical shift values were reported on $\delta$ scale in parts per million (ppm), relative to TMS $(\delta=0.00 \mathrm{ppm})$ and the ${ }^{13} \mathrm{C}$ chemical shift values were reported relative to $\mathrm{CDCl}_{3}(\delta=77 \mathrm{ppm})$.

\subsubsection{Fourier transform infrared spectroscopy (FT-IR)}

The infrared spectroscopy data of all starting materials were recorded on a Tensor II FT-IR spectrophotometer (Bruker Optik $\mathrm{GmbH}$ ) over the range of $4000-400 \mathrm{~cm}^{-1}$ by pressed pellet method using diamond. The spectra were acquired by the accumulation of 256 scans with $4 \mathrm{~cm}^{-1}$ resolution via Opus 7.5 software. The absorption values were represented in $\mathrm{cm}^{-1}$.

\subsubsection{HPLC}

The chromatographic experiments were carried out on Nexera-X2 model ultra-high-performance liquid chromatography technique (UHPLC) (Agilent Technology 1290 Infinity, Japan) equipped with a photodiode array detector (DAD). The Agilent Software was utilized for monitoring the process, data acquisition and system control. The test sample solutions were prepared in diluent, a mixture of methanol (MeOH)-water $(20: 80, \mathrm{v} / \mathrm{v})$. The analysed substances were carried out on a reverse phase Poroshell 120, EC-C8 $(4.6 \mathrm{~mm} \times$ $150 \mathrm{~mm}, 2.7 \mathrm{um}$ ) column (Agilent Technologies, CA, USA) by maintaining column temperature at 30 ${ }^{\circ} \mathrm{C}$. Mobile phase A was pure HPLC water, and methanol was used as mobile phase $B$. The injection volume and wavelength were fixed at 5 $\mu \mathrm{L}$ and $254 \mathrm{~nm}$, respectively, and the data were acquired by using gradient elution system at a flow rate of $1.0 \mathrm{~mL} / \mathrm{min}$. The separation was accomplished by employing a linear gradient programme as $t_{\min } / A: B: \quad t=3 \min / 70: 30$, $\mathrm{t}=6 \mathrm{~min} / 50: 50, \quad \mathrm{t}=11 \mathrm{~min} / 50: 50, \quad$ and $t=12 \min / 70: 30$ with an equilibration time of 1.0 $\min$.

\subsubsection{Implementation of NRTL model}

Reliable thermodynamic methods are extremely important for process simulation and design of this extraction process. This LLE experimental data was used to assess the LLE predictive capability of some liquid-phase models. The mathematical models used in this study were NRTL. Both models were used as programmed into the Aspen Plus simulator. The Non-Random-TwoLiquid (NRTL) model (GMRENON) calculated liquid activity coefficients. It is recommended for highly non-ideal chemical systems and can be used for VLE and LLE applications. The design of an identical platform was conducted in Aspen Plus v10 as described in Scheme 2. The binary interaction parameters of NRTL models were obtained using the data regression of the Aspen Plus simulator. These binary interaction parameters were determined by minimizing the deviation between the experimental data and model-calculated values. The equation for the NRTL model is:

$$
\ln \gamma_{i}=\frac{\sum_{j} x_{j} \tau_{j i} G_{j i}}{\sum_{k}^{n} x_{k} G_{k i}}+\sum_{j}^{n} \frac{x_{j} G_{i j}}{\sum_{k}^{n} x_{k} G_{k j}}\left|\tau_{i j}-\frac{\sum_{m}^{n} x_{m} \tau_{m j} G_{m j}}{\sum_{k}^{n} x_{k} G_{k j}}\right|_{\text {for } T_{\text {lower }} \leq T \leq T_{\text {upper }}}
$$




$$
\begin{aligned}
& G_{i j}=\exp \left(-\alpha_{i j} \tau_{i j}\right) \\
& \tau_{i j}=a_{i j}+\frac{b_{i j}}{T} e_{i j} \ln T+f_{i j} T \\
& \alpha_{i j}=c_{i j}+d_{i j}(T-273.15 K) \\
& \tau_{i i}=0 \\
& G_{i i}=1
\end{aligned}
$$

aij, bij, eij, and fij are unsymmetrical. That is, aij may not be equal to aji, etc.

\section{Results and discussion}

\subsection{Partition coefficients}

Partition coefficients of the 4 molecules of interest were measured experimentally and predicted computationally via different methods such as the HPLC and the slice-selective NMR. Experimental measurements were obtained by conducting shaking flasks experiments where biphasic samples were prepared, shaken, then left to settle. Finally, each phase was extracted and analysed separately with HPLC or NMR. To calculate the extraction coefficient: the formula below was applied

$$
\mathrm{K}(\text { ext })=\frac{C_{\text {Extract }}}{C_{\text {Residue }}}
$$

The experimental measurements of partition coefficients of the analytes of interest were important to build a robust NRTL method capable of simulating the liquid-liquid extraction in the real world and also to search reliably for the global solution to achieve the optimum extraction. From the HPLC chromatograms, the samples extracted from the aqueous and organic phases gave an average of 1.20 for the partition coefficient. With slice-selective NMR, this value was estimated to 1.30. It was also possible to assess the partition coefficients for the morpholine (0.029) and the trimethoxybenzoic acid (0.09).

When the NRTL method was adjusted with the regression binary parameters, it was possible to get indirectly the partition coefficient by estimating the composition of each stream in the platform.

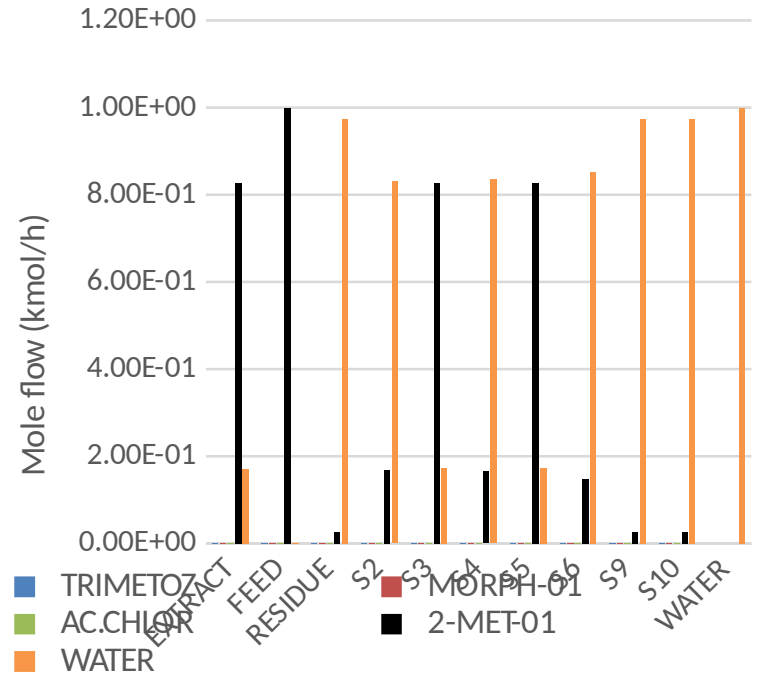

Graph 2. Flow rates of the different components of the extraction mixtures at all the streams of the LLE platform.

The partitioning of the analytes between the organic and aqueous phases were illustrated in Graph 2. It is clear that the dominant concentrations of water and methyl tetrahydrofuran were hiding a more relevant information about the analyte. For the sake of clarity, the concentration of the solvents was omitted in Graph 3.

The simulated platform was initially fed with a same amount of trimethoxybenzoic acid and morpholine $\left(7.10^{-3} \mathrm{kmol} / \mathrm{h}\right)$. The residue stream was practically pure from these two impurities after three stages of extraction. It is noteworthy that the concentration of trimetozine decreased in the downstream of the platform due to the expected partitioning of this molecules in the different compartment of the platform. The extract outlet was rich in trimetozine with a flow rate of $1.7 \cdot 10^{-4} \mathrm{kmol} / \mathrm{h}$ ).

Streams composition by omitting the water and Me-THF

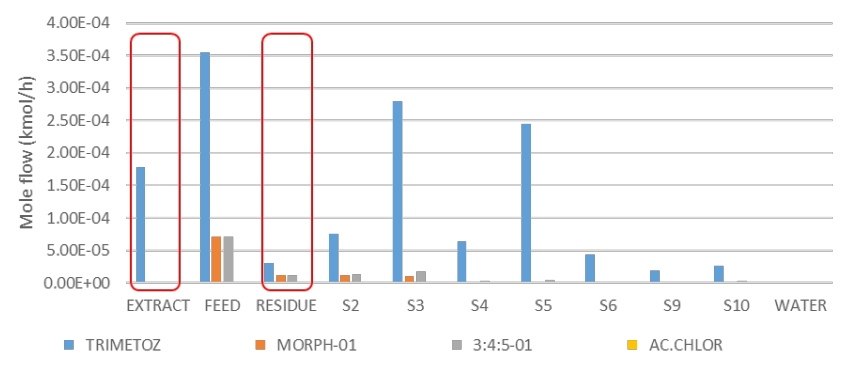

Graph 3. The flow rates of the trimetozine, morpholine, trimethoxybenzoic acid and trimethoxybenzoyl chloride at the different streams of the platform.

The partition coefficient of trimetozine may also be measured for individual settler. This feature in the simulation enable the 
assessment of the performance of the extraction platform in terms of number of stages included. For instance, the partition coefficient was estimated to be 3.2 at the first settler and 2.64 at the last settler. This variation can be explained by the sensitivity of the portioning of a given compound towards its concentration or the concentration of the coexisting molecules.

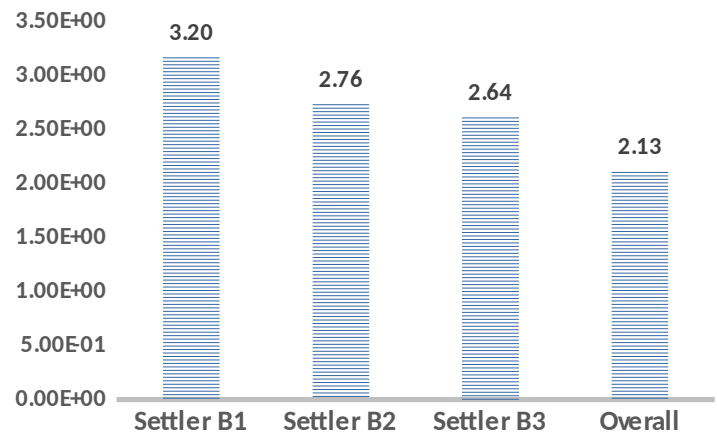

Graph 4. Partition coefficients of trimetozine in the different settlers of the LLE platform and the overall extraction distribution.

\subsection{Sensitivity analysis}

In order to better understand the effect of each process variable on the yield of trimetozine in the downstream of the platform, the temperature of the first mixer and the flow rate of water. The yield of extraction was affected by the temperature in the mixer 1 and is optimum in the range between 15 and 25으. Graph 5 showed that the yield increased when the flow rate decreased.

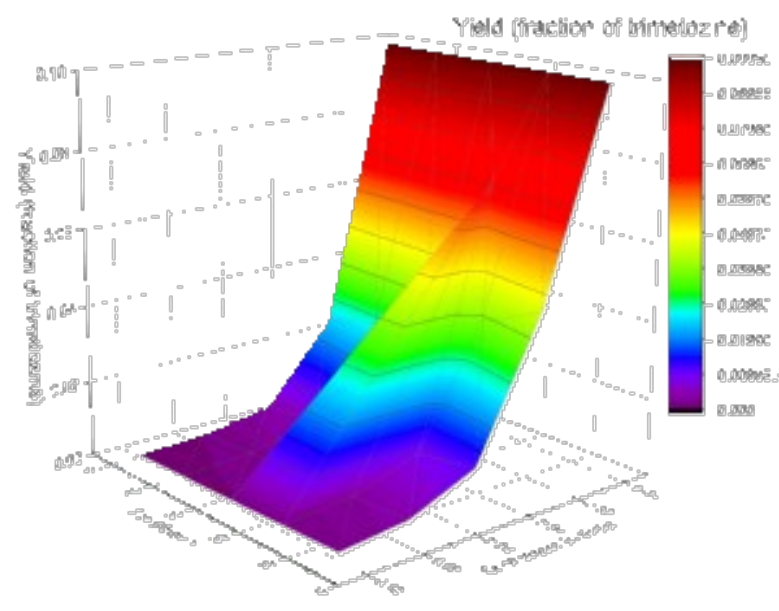

Graph 5. The yield of extraction as a function of the flow rate of the washing solvent (water) and the temperature of the first mixer.

The binary parameters for the NRTL model were regressed via Aspen Plus simulator using experimental data gathered from the measurement of the composition of the immiscible phases of water/methyltetrahydrofuran. The $a_{i j}$ parameters were set to zero during the regression because the equilibrium compositions were measured at a constant temperature.

The selection of the optimum conditions to achieve the highest extraction yield of Trimetozine was based on global optimization. All the process factors were included in order to search for the best combination of these factors. The temperatures in the three mixers, and the flow rates of the feed and the extractant were chosen.

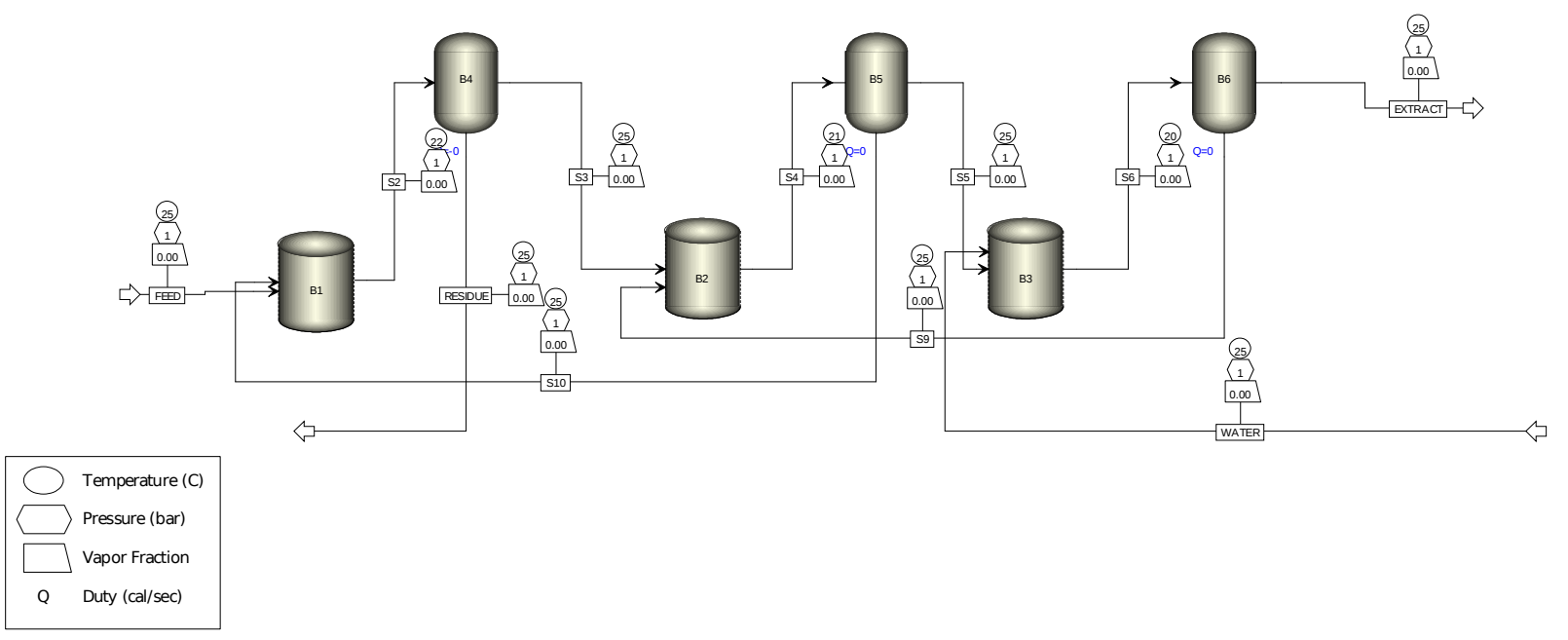

Scheme 1. Aspen worksheet of the counter current liquid-liquid extraction with three stages of the mixers and decanters.

\section{Conclusions}

The NRTL model was implemented and its parameters were optimised in LabVIEW in 
order to simulate a 3-stages countercurrent liq-liq extraction. The partition coefficients of the different analytes were estimated with different techniques experimentally and in silico. HPLC and slice-selective NMR were exploited to evaluate the partition of trimetozine between the organic and the aqueous phase. Aspen sensitivity analysis was also conducted on the optimised NRTL model to assess the effect of certain process variable on the yield of extract.

\section{AUTHOR INFORMATION}

\section{Corresponding Author}

* (Word Style

"FA Corresponding Author Footnote"). Give contact information for the author(s) to whom correspondence should be addressed.

\section{Present Addresses}

tIf an author's address is different than the one given in the affiliation line, this information may be included here.

\section{Author Contributions}

The manuscript was written through contributions of all authors. / All authors have given approval to the final version of the manuscript. / \$These authors contributed equally. (match statement to author names with a symbol)

\section{Funding Sources}

Any funds used to support the research of the manuscript should be placed here (per journal style).

\section{Notes}

Any additional relevant notes should be placed here.

\section{ACKNOWLEDGMENT}

(Word Style "TD_Acknowledgments"). Generally, the last paragraph of the paper is the place to acknowledge people (dedications), places, and financing (you may state grant numbers and sponsors here). Follow the journal's guidelines on what to include in the Acknowledgement section.

\section{ABBREVIATIONS}

CCR2, CC chemokine receptor 2; CCL2, CC chemokine ligand 2; CCR5, CC chemokine receptor 5; TLC, thin layer chromatography.

\section{REFERENCES}

1. Albright's chemical engineering handbook. Choice Rev. Online (2013). doi:10.5860/choice.46-4467

2. Zhang, J. \& Hu, B. Liquid-Liquid Extraction (LLE). in Separation and Purification Technologies in Biorefineries 61-78 (John Wiley \& Sons, Ltd, 2013). doi:10.1002/9781118493441.ch3

3. Wei, W. et al. Selective recovery of Au(III), Pt(IV), and $\mathrm{Pd}$ (II) from aqueous solutions by liquid-liquid extraction using ionic liquid Aliquat-336. J. Mol. Liq. (2016). doi:10.1016/j.molliq.2016.01.016

4. Jiao, T. et al. The new liquid-liquid extraction method for separation of phenolic compounds from coal tar. Chem. Eng. J. (2015). doi:10.1016/j.cej.2014.12.071

5. Sas, O. G. Domínguez, I., González, B. \& Domínguez, A Liquid-liquid extraction of phenolic compounds from water using ionic liquids: Literature review and new experimental data using [C2mim]FSI. J. Environ. Manage. (2018). doi:10.1016/j.jenvman.2018.09.042

6. Maruyama, T., Ishizu, N., Eguchi, Y., Hosogi, T. \& Goto M. Liquid-liquid extraction of enzymatically synthesized functional RNA oligonucleotides using reverse micelles with a DNA-surfactant. Chem. Commun. (2016). doi:10.1039/c6cc06985a

7. Rezaee, M., Yamini, Y. \& Faraji, M. Evolution of dispersive liquid-liquid microextraction method. Journal of Chromatography A doi:10.1016/j.chroma.2009.11.088

Silvestre, C. I. C., Santos, J. L. M., Lima, J. L. F. C. \& Zagatto, E. A. G. Liquid-liquid extraction in flow analysis: A critical review. Anal. Chim. Acta 652, 54-65 (2009).

9. Güell, R., Fontàs, C., Salvadó, V. \& Anticó, E. Modelling of liquid-liquid extraction and liquid membrane separation of arsenic species in environmental matrices. Sep. Purif. Technol. 72, 319-325 (2010).

10. Alimuddin, $M$. et al. Determination of $\log D$ via automated microfluidic liquid-liquid extraction. J. Med. Chem. 51, 5140-5142 (2008)

11. Chouai, a., Cabassud, M., Le Lann, M. V., Gourdon, C. \& Casamatta, G. Use of neural networks for liquid-liquid extraction column modelling: an experimental study. Chem. Eng. Process. Process Intensif. 39, 171-180 (2000).

12. Binous, $\mathrm{H}$. Liquid-liquid equilibrium and extraction using Mathematica?? Comput. Educ. J. 16, 78-81 (2006).

13. Homrich, P. O. B., Dias, L. G., Mariutti, L. R. B. Bragagnolo, N. \& Ceriani, R. Liquid-liquid equilibria and density data for pseudoternary systems of refined soybean oil + (hexanal, or heptanal, or butyric acid, or valeric acid, or caproic acid, or caprylic acid) + dimethyl sulfoxide at $298.15 \mathrm{~K}$. J. Chem. Thermodyn. (2019). doi:10.1016/j.jct.2018.10.030

14. Gouveia, A. S. L., Oliveira, F. S., Kurnia, K. A. \& Marrucho, I. M. Deep Eutectic Solvents as Azeotrope Breakers: Liquid-Liquid Extraction and COSMO-RS Prediction. ACS Sustain. Chem. Eng. (2016). doi:10.1021/acssuschemeng.6b01542

15. Birajdar, S. D., Padmanabhan, S. \& Rajagopalan, S Rapid solvent screening using thermodynamic models for recovery of 2,3-butanediol from fermentation by liquid-liquid extraction. J. Chem. Eng. Data 59, 24562463 (2014).

16. Shah, M. R. \& Yadav, G. D. Prediction of liquid-liquid equilibria of (aromatic+aliphatic+ionic liquid) systems using the Cosmo-SAC model. J. Chem. Thermodyn. 49, 62-69 (2012).

17. Maurer, G. Modeling the liquid-liquid equilibrium for the recovery of carboxylic acids from aqueous solutions. Fluid Phase Equilib. 241, 86-95 (2006).

18. White, T. D. et al. Development of a continuous Schotten-Baumann route to an acyl sulfonamide. Org. Process Res. Dev. 16, 939-957 (2012).

19. Kawahara, K. \& Ofuji, T. Simultaneous determination of glucuronides of trimetozine in human urine by gas chromatography. J. Chromatogr. B Biomed. Sci. Appl. 
(1982). doi:10.1016/S0378-4347(00)81858-7

20. Vanderveen, J. R. et al. Non-random two-liquid modelling of switchable-hydrophilicity solvent systems: N,N-Dimethylcyclohexanamine, water, and toluene. Fluid Phase Equilib. doi:10.1016/j.fluid.2015.09.032

(2016)

21. Thomsen, K. Modeling electrolyte solutions with the extended universal quasichemical (UNIQUAC) model. Pure Appl. Chem. (2005). doi:10.1351/pac200577030531

22. Do Carmo, F. R., Evangelista, N. S., De Santiago-Aguiar, R. S., Fernandes, F. A. N. \& De Sant'Ana, H. B.
Evaluation of optimal activity coefficient models for modeling and simulation of liquid-liquid equilibrium of biodiesel + glycerol + alcohol systems. Fuel (2014). doi:10.1016/j.fuel.2014.01.108

23. Yang, X. D. et al. Silica gel-mediated amide bond formation: An environmentally benign method for liquid-phase synthesis and cytotoxic activities of amides. J. Comb. Chem. (2010). doi:10.1021/cc900135f

24. Khan, K. M. et al. Leishmanicidal potential of $\mathrm{N}$ substituted morpholine derivatives: Synthesis and structure-activity relationships. Nat. Prod. Res. 23, 479484 (2009). 


\title{
Steady-state simulation of the counter current liquid-liquid extrac- tion: Trimetozine synthesis as a case study
}

\author{
Zied Hosni, ${ }^{a}$ Ian Houson, ${ }^{\mathrm{a}}$ Brahim BenYahia, ${ }^{\mathrm{b}}$ Alastair Florence ${ }^{\mathrm{a}}$ \\ ${ }^{a}$ EPSRC Centre for Innovative Manufacturing in Continuous Manufacturing and Crystallisation, Department of Chemical \\ and Process Engineering, University of Strathclyde, James Weir Building, 75 Montrose Street, Glasgow G1 1XJ, United \\ Kingdom \\ ${ }^{b}$ Loughborough University, Loughborough, United Kingdom
}

KEYWORDS Liquid-liquid extraction, impurities rejection, Aspen simulation, Automation, feedback control

\begin{abstract}
The countercurrent liquid-liquid extraction is a crucial step in industrial process to purify and extract a compound of interests for its impurities. This step requires generally challenging and time-consuming optimisation of numerous factors that affect the overall yield of extraction and the energy needed. The simulation of this process has been investigated in this paper using a NonRandom Two Liquid model implemented as a thermodynamic method in Aspen. The outcome of this model enables the evaluation of the partition coefficients of the different analytes of a mixtures at the different compartments of extraction platform. In addition, this steady-state model allows a more straightforward optimisation of the factors that drive the performance of extraction.
\end{abstract}

\section{Introduction}

Liquid-liquid extraction is a major task in the chemical engineering field. ${ }^{1}$ It requires usually a typical ternary system process: solute, diluent, and extractant. Solute, which is dissolved in diluent, is extracted from the diluent and dissolved into another solvent, the extractant. ${ }^{2}$ It separates chemicals from one solution to another based on the different solubility of the solute in two solvents. It is considered as a pre-treatment in many analytical applications in order to pre-concentration and/or separation of multiple analytes such as ultra-trace metal and metalloid species, ${ }^{3}$ phenolic compounds, ${ }^{4,5}$ surfactants, ${ }^{6}$ pharmaceuticals, ${ }^{7}$ etc. Despite its importance, LLE is a limiting step to achieve the desired analytical efficiency. It increases the selectivity by concentrating the analyte from a large sample volume and promote its isolation from matrix-interfering species. This traditional technique still suffers from several disadvantages because it is labour-intensive and time-consuming, which leads to a significant need for large amount of chemicals that can be harmful, expensive and environmentally hazardous and can form eventually emulsions difficult to separate under certain conditions. ${ }^{8}$ The distribution $\mathrm{D}$ of the solute to be extracted among the extracting solvent and the diluent can be described as follows:

$$
D=\frac{S_{e}}{\mathrm{~S}_{\mathrm{d}}}
$$

where $\mathrm{S}_{\mathrm{e}}$ : solute concentration in extractant $(\mathrm{mol} / \mathrm{L}), \mathrm{S}_{\mathrm{d}}$ : solute concentration in diluent $(\mathrm{mol} / \mathrm{L})$.

In the Anticó group, Supported Liquid Membrane (SLM) was used to investigate the transport of arsenic species. They built a thermodynamic model that corresponds to the extraction for both $\mathrm{As}(\mathrm{V})$ and As(III) species by employing data generated from the variation of the conditions that affect the extraction such as the organic solvents and $\mathrm{pH}$ of the aqueous phase. The SLM enabled the separation of $\mathrm{As}(\mathrm{V})$ and $\mathrm{As}(\mathrm{III})$ species based on their different kinetic behaviors. Taking into account the good results obtained in liquid-liquid experiments, a Supported Liquid Membrane (SLM) system was developed based on the best separation conditions. ${ }^{9}$
In order to assess molecules lipophilicity, Alimuddin and co-workers determined the octanol-water distribution coefficient $\log \mathrm{D}$ at $\mathrm{pH} 7.4$ for 26 compounds in an automated microfluidic liquid-liquid extraction and compared to the results obtained from shakeflask methods. Excellent correlation between the values obtained via both methods was achieved $\left(\mathrm{R}^{2}=0.994\right)$. The authors claimed that this technique based on a PTFE membrane extraction is amenable to automation, enabling high-throughput determination of large compound collections. ${ }^{10}$

Artificial Neural Networks were applied to build a model that translates the physicochemical behaviour of a pulsed liquid-liquid extraction column. A pulsed liquid-liquid extraction column for the separation of oxalic acid from aqueous solutions using a mixture of tributylphosphate and dodecane as a selective solvent were employed. The training of the Neural Network was carried out offline with the utilisation of the cross-validation in order to achieve a better system representation of noisy data. 6000 different patterns of inputs-outputs were employed for the training and 2992 other patterns were used as a test dataset. The inputs of the algorithm represented the past and the present collected data $(\mathrm{pH}$, conductivity, the concentration) and the outputs represented the future estimated measured $\mathrm{pH}$ and conductivity only. ${ }^{11}$

Binous implemented in Mathematica ${ }^{\circledR}$ a new approach to solve liquid-liquid extraction problems. He considered a ternary mixture of ethanol-water and benzene at $25^{\circ} \mathrm{C}$ and he employed the software to solve the system of the nonlinear algebraic equations that represent the equilibrium relation between the two liquid phases. He studied also the separation of acetic acid from water using isopropyl ether in single-feed counter current extractor and two feed extraction columns. In addition, he used the Hunter-Nash method to determine the number of equilibrium stages needed to achieve a particular raffinate specifications. Finally, the McCabe-Thiele diagram was used to compare the previously obtained results. ${ }^{12}$

In the Rajagopalan group, different thermodynamic models were used for the recovery of 2,3-Butanediol (BDO) from fermentation by liquid-liquid extraction. Experimental results of the distribution coefficients $\left(\mathrm{K}_{\mathrm{d}}\right)$ were compared with the data generated from two 
theoretical models: Conductor-like Screening Model-Real Solvents (COSMO-RS) and Universal Functional group Activity Coefficient model (UNIFAC-LL). These models permitted to calculate the activity coefficients $\left(\gamma^{\infty}\right)$ of BDO in various solvents. The authors claimed that both models provided qualitative trends of the prediction and the ranking of the solvents according to the experimental references. Among the two quantum-based thermodynamic models, UNIFAC-LL ${ }^{13}$ outperformed the COSMO-RS ${ }^{14}$. It was also highlighted that the integration of the updated parameters from the UNIFAC model in the UNIFAC-LL calculated provided better results, much closer to the experimental values. The $\left(K_{d}\right)$ values were also calculated in Aspen Plus software. ${ }^{15}$

Thermodynamic-based modelling was also investigated to predict the liquid-liquid equilibria of the (aromatic + aliphatic + ionic liquid) ternary systems. COSMO-SAC is a variant of the COSMO-RS model and can predict thermodynamic equilibria without any group contribution parameters or experimental data. Only quantum chemical calculations are required, followed by the application of a thermodynamic model. It can also handle variation in concentration and temperature. ${ }^{16}$

Maurer designed a model of the liquid-liquid equilibrium for the recovery of carboxylic acids from aqueous solutions. The separation is driven by the affinity to the organic phase of the weak complex formed between a carboxylic acid and an amine. The author chose a framework based on the equilibrium between citric acid tri,n-octylamine and toluene. The model was constituted of a chemical (the chemical reaction equilibrium) and a physical (the excess Gibbs energy) contribution. In addition, the model allowed the evaluation of the influence of strong electrolyte (salts) on the phase equilibrium. ${ }^{17}$

The purification of an organic molecule from its by-products within the crude of the synthesis is a crucial step before the crystallisation process because the presence of impurities has a crucial impact on the polymorphism of the solid state. The Schotten-Baumann synthesis was investigated heavily as it is providing the amide function from an amine and acid chloride. ${ }^{18}$ This reaction has the particularity to use two immiscible solvent, usually water as the aqueous phase and a polar non-protic organic solvent as the organic phase. The utilisation of the aqueous phase assists the elimination of the acid that is produced in the organic phase. The addition of base such as the sodium Carbonate inhibits also the protonation of the amine by the generated acid and prevents the reduction of the nucleophilicity of the nitrogen in the amine function. The Trimetozine synthesis is a popular example of this reaction as illustrated in Graph $1 .{ }^{19}$

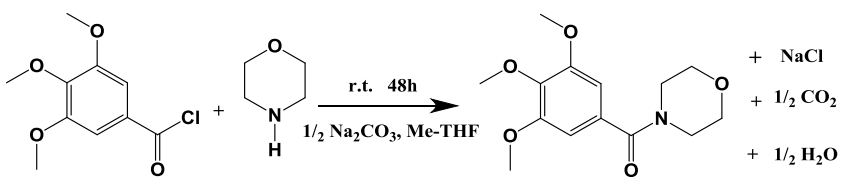

Graph 1. Synthesis of Trimetozine in Me-THF in presence of sodium carbonate.

This commercialised sedative is produced in the presence of three main impurities: unreacted morpholine and trimethoxybenzoyl chloride, and the hydrolysis of the acid chloride giving the trimethoxybenzoic acid. In the present paper, we applied different thermodynamic models implemented in Aspen to simulate the partition of the Trimetozine and its corresponding impurities between the organic and the aqueous phase. We optimised the parameters of three different models: the Non-Random-Two Liquid model, ${ }^{20}$ the
UNIversal QUAsiChemical (UNIQUAC) ${ }^{21}$ and the UNIQUAC Functional-group Activity Coefficients (UNIFAC) ${ }^{22}$ models. These three models were exploited to drive a global optimisation in order to find the optimum process conditions to achieve the highest yield of Trimetozine extraction at the desired purity level using a simulated three-stages countercurrent liquid-liquid extraction.

\section{Experiments}

\subsection{Materials and reagents}

The chemicals employed for the synthesis of trimetozine were obtained from Sigma Aldrich (UK). Morpholine was provided by Santa Cruz (US) and the trimethoxybenzoic acid was purchased from Alfa Aeser (UK). Sodium carbonate and butanol were supplied by VWR (UK). HPLC grade acetonitrile, water, methanol were provided by VWR (UK). $\mathrm{D}_{2} \mathrm{O}$ and deuterated chloroform were purchased from Sigma-Aldrich (UK).

\subsection{Trimetozine synthesis}

To a mixture of morpholine (87.1 mg, $1 \mathrm{mmol}$ ) dissolved Me-THF $(25 \mathrm{~mL})$ was added a mixture of sodium carbonate $(48.1 \mathrm{mg}, 2$ $\mathrm{mmol}$ ), and the resultant mixture was stirred at room temperature for $15 \mathrm{~min}$ and then trimethoxybenzoyl chloride $(230.6 \mathrm{mg}, 1$ $\mathrm{mmol}$ ) was added. The mixture was stirred for $48 \mathrm{~h}$. On completion, the solid was filtered with a sintered glass funnel. The filtrate was evaporated on a rotary evaporator, the residue was dried on a twostage pump (high vacuum) and the resultant product was recrystallized and dried in a desiccator, while the liquid products were purified by vacuum distillation. ${ }^{23,24}{ }^{1} \mathrm{H} \mathrm{NMR}\left(300 \mathrm{MHz}, \mathrm{CDCl}_{3}\right) \delta 6.61$ (s, 2H, Ar-H), 3.86 (s, 6H, 2×OCH3), 3.85 (s, 3H, OCH3), 3.69 (br, $\mathrm{s}, 8 \mathrm{H}, 4 \times \mathrm{CH}_{2}$ ).

\subsubsection{Nuclear magnetic resonance spectroscopy (NMR)}

${ }^{1} \mathrm{H}$ and ${ }^{13} \mathrm{C}$ NMR experiments were performed on a Bruker 400 $\mathrm{MHz}$ NMR spectrometer (Bruker, Falladon, Switzerland) using deuterated chloroform $\left(\mathrm{CDCl}_{3}\right)$ as a solvent and tetramethylsilane (TMS) as an internal standard. The ${ }^{1} \mathrm{H}$ chemical shift values were reported on $\delta$ scale in parts per million ( $\mathrm{ppm})$, relative to TMS $(\delta=$ $0.00 \mathrm{ppm})$ and the ${ }^{13} \mathrm{C}$ chemical shift values were reported relative to $\mathrm{CDCl}_{3}(\delta=77 \mathrm{ppm})$.

\subsubsection{Fourier transform infrared spectroscopy (FT-IR)}

The infrared spectroscopy data of all starting materials were recorded on a Tensor II FT-IR spectrophotometer (Bruker Optik $\mathrm{GmbH}$ ) over the range of $4000-400 \mathrm{~cm}^{-1}$ by pressed pellet method using diamond. The spectra were acquired by the accumulation of 256 scans with $4 \mathrm{~cm}^{-1}$ resolution via Opus 7.5 software. The absorption values were represented in $\mathrm{cm}^{-1}$.

\subsubsection{HPLC}

The chromatographic experiments were carried out on Nexera-X2 model ultra-high-performance liquid chromatography technique (UHPLC) (Agilent Technology 1290 Infinity, Japan) equipped with a photodiode array detector (DAD). The Agilent Software was utilized for monitoring the process, data acquisition and system control. The test sample solutions were prepared in diluent, a mixture of methanol $(\mathrm{MeOH})$-water $(20: 80$, v/v). The analysed substances were carried out on a reverse phase Poroshell 120, EC-C8 (4.6mm x 150mm, 2.7um) column (Agilent Technologies, CA, USA) by maintaining column temperature at $30^{\circ} \mathrm{C}$. Mobile phase A was pure HPLC water, and methanol was used as mobile phase B. The injection volume and wavelength were fixed at $5 \mu \mathrm{L}$ and 
$254 \mathrm{~nm}$, respectively, and the data were acquired by using gradient elution system at a flow rate of $1.0 \mathrm{~mL} / \mathrm{min}$. The separation was accomplished by employing a linear gradient programme as $t_{\min } / A: B: \quad t=3 \min / 70: 30, \quad t=6 \mathrm{~min} / 50: 50, \quad t=11 \mathrm{~min} / 50: 50$, and $t=12 \mathrm{~min} / 70: 30$ with an equilibration time of $1.0 \mathrm{~min}$.

\subsubsection{Implementation of NRTL model}

Reliable thermodynamic methods are extremely important for process simulation and design of this extraction process. This LLE experimental data was used to assess the LLE predictive capability of some liquid-phase models. The mathematical models used in this study were NRTL. Both models were used as programmed into the Aspen Plus simulator. The Non-Random-Two-Liquid (NRTL) model (GMRENON) calculated liquid activity coefficients. It is recommended for highly non-ideal chemical systems and can be used for VLE and LLE applications. The design of an identical platform was conducted in Aspen Plus v10 as described in Scheme 2. The binary interaction parameters of NRTL models were obtained using the data regression of the Aspen Plus simulator. These binary interaction parameters were determined by minimizing the deviation between the experimental data and model-calculated values. The equation for the NRTL model is:

$$
\ln \gamma_{i}=\frac{\sum_{j} x_{j} \tau_{j i} G_{j i}}{\sum_{k}^{n} x_{k} G_{k i}}+\sum_{j}^{n} \frac{x_{j} G_{i j}}{\sum_{k}^{n} x_{k} G_{k j}}\left(\tau_{i j}-\frac{\sum_{m}^{n} x_{m} \tau_{m j} G_{m j}}{\sum_{k}^{n} x_{k} G_{k j}}\right)_{f o r T_{l o w e r} \leq T \leq T_{u p p e r}}
$$

where

$$
\begin{gathered}
G_{i j}=\exp \left(-\alpha_{i j} \tau_{i j}\right) \\
\tau_{i j}=a_{i j}+\frac{b_{i j}}{T} e_{i j} \ln T+f_{i j} T \\
\alpha_{i j}=c_{i j}+d_{i j}(T-273.15 K) \\
\tau_{i i}=0 \\
G_{i i}=1
\end{gathered}
$$

$a i j, b i j, e i j$, and $f i j$ are unsymmetrical. That is, aij may not be equal to aji, etc.

\section{Results and discussion}

\subsection{Partition coefficients}

Partition coefficients of the 4 molecules of interest were measured experimentally and predicted computationally via different methods such as the HPLC and the slice-selective NMR. Experimental measurements were obtained by conducting shaking flasks experiments where biphasic samples were prepared, shaken, then left to settle. Finally, each phase was extracted and analysed separately with HPLC or NMR. To calculate the extraction coefficient: the formula below was applied

$$
K(\text { ext })=\frac{\boldsymbol{C}_{\text {Extract }}}{\boldsymbol{C}_{\text {Residue }}}
$$

The experimental measurements of partition coefficients of the analytes of interest were important to build a robust NRTL method capable of simulating the liquid-liquid extraction in the real world and also to search reliably for the global solution to achieve the optimum extraction. From the HPLC chromatograms, the samples extracted from the aqueous and organic phases gave an average of 1.20 for the partition coefficient. With slice-selective NMR, this value was estimated to 1.30 . It was also possible to assess the partition coefficients for the morpholine (0.029) and the trimethoxybenzoic acid (0.09).

When the NRTL method was adjusted with the regression binary parameters, it was possible to get indirectly the partition coefficient by estimating the composition of each stream in the platform.

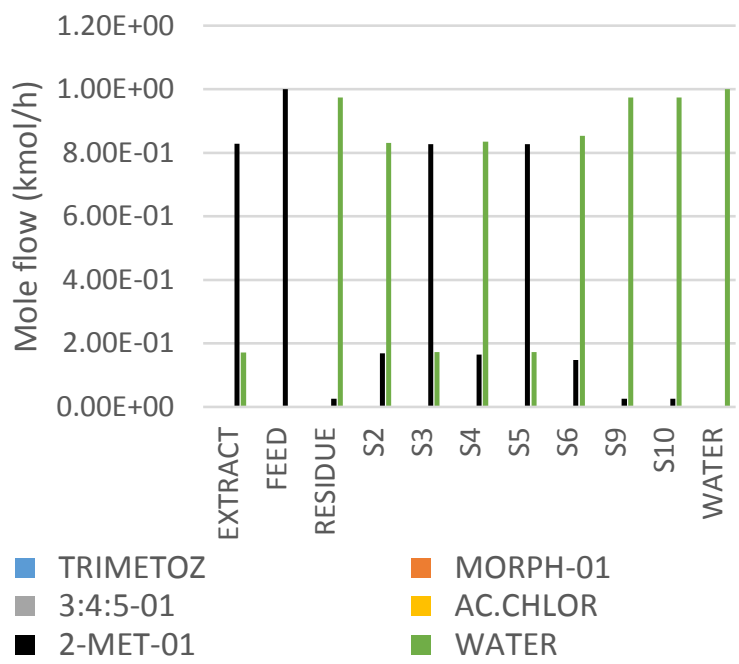

Graph 2. Flow rates of the different components of the extraction mixtures at all the streams of the LLE platform.

The partitioning of the analytes between the organic and aqueous phases were illustrated in Graph 2. It is clear that the dominant concentrations of water and methyl tetrahydrofuran were hiding a more relevant information about the analyte. For the sake of clarity, the concentration of the solvents was omitted in Graph 3.

The simulated platform was initially fed with a same amount of trimethoxybenzoic acid and morpholine $\left(7.10^{-3} \mathrm{kmol} / \mathrm{h}\right)$. The residue stream was practically pure from these two impurities after three stages of extraction. It is noteworthy that the concentration of trimetozine decreased in the downstream of the platform due to the expected partitioning of this molecules in the different compartment of the platform. The extract outlet was rich in trimetozine with a flow rate of 1.7.10 $\left.{ }^{4} \mathrm{kmol} / \mathrm{h}\right)$. 
Streams composition by omitting the water and Me-THF

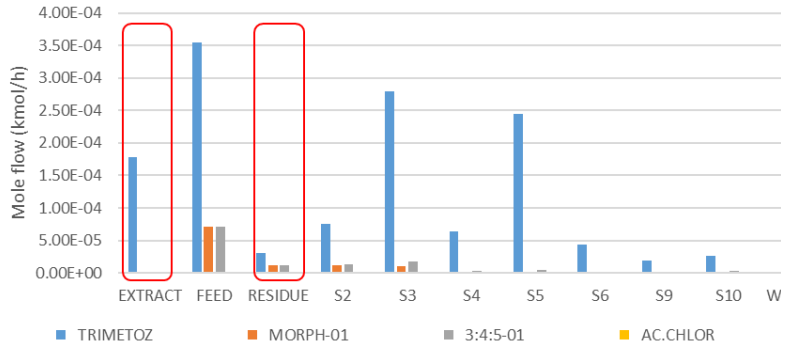

Graph 3. The flow rates of the trimetozine, morpholine, trimethoxybenzoic acid and trimethoxybenzoyl chloride at the different streams of the platform.

The partition coefficient of trimetozine may also be measured for individual settler. This feature in the simulation enable the assessment of the performance of the extraction platform in terms of number of stages included. For instance, the partition coefficient was estimated to be 3.2 at the first settler and 2.64 at the last settler. This variation can be explained by the sensitivity of the portioning of a given compound towards its concentration or the concentration of the coexisting molecules.

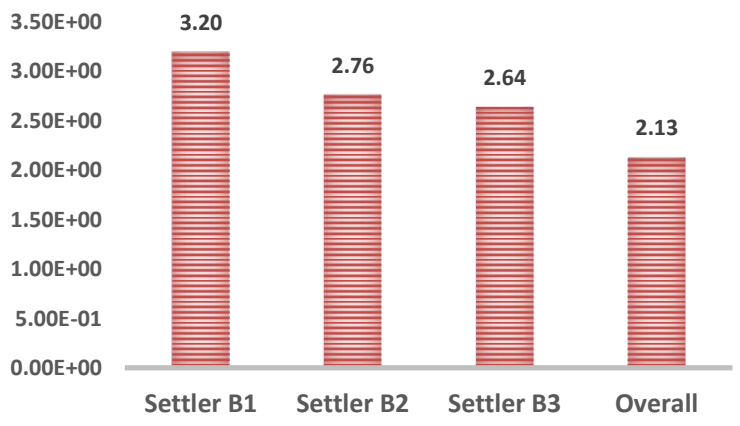

Graph 4. Partition coefficients of trimetozine in the different settlers of the LLE platform and the overall extraction distribution.

\subsection{Sensitivity analysis}

In order to better understand the effect of each process variable on the yield of trimetozine in the downstream of the platform, the temperature of the first mixer and the flow rate of water. The yield of extraction was affected by the temperature in the mixer 1 and is optimum in the range between 15 and $25^{\circ} \mathrm{C}$. Graph 5 showed that the yield increased when the flow rate decreased.

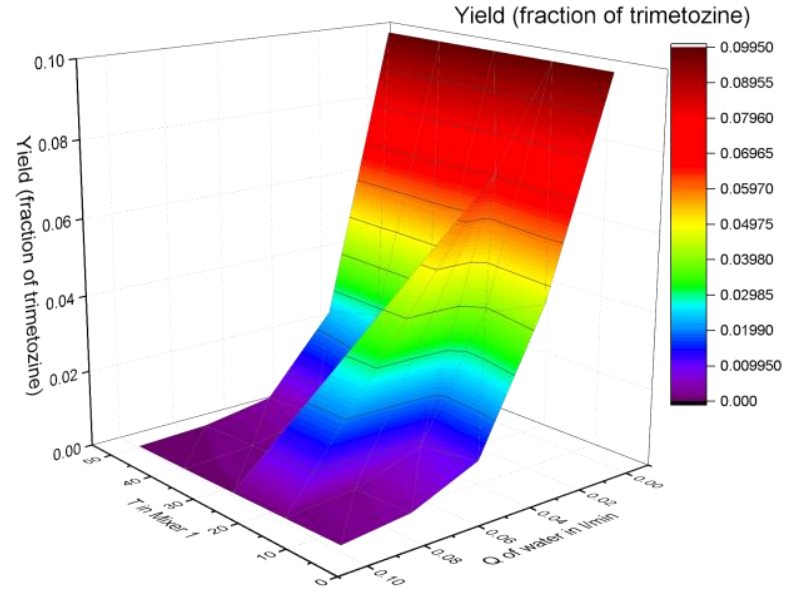

Graph 5. The yield of extraction as a function of the flow rate of the washing solvent (water) and the temperature of the first mixer.

The binary parameters for the NRTL model were regressed via Aspen Plus simulator using experimental data gathered from the measurement of the composition of the immiscible phases of water/methyltetrahydrofuran. The $\mathrm{a}_{\mathrm{ij}}$ parameters were set to zero during the regression because the equilibrium compositions were measured at a constant temperature.

The selection of the optimum conditions to achieve the highest extraction yield of Trimetozine was based on global optimization. All the process factors were included in order to search for the best combination of these factors. The temperatures in the three mixers, and the flow rates of the feed and the extractant were chosen.

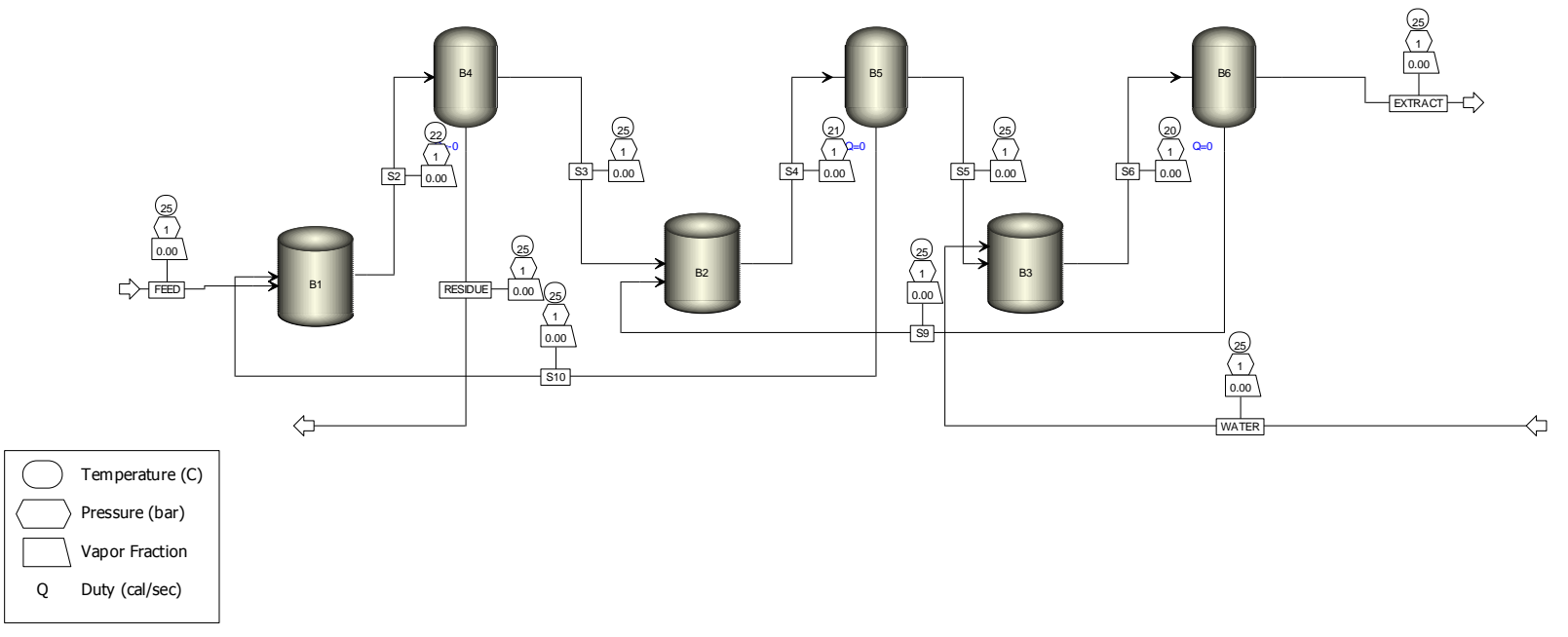


Scheme 1. Aspen worksheet of the counter current liquid-liquid extraction with three stages of the mixers and decanters.

\section{Conclusions}

The NRTL model was implemented and its parameters were optimised in LabVIEW in order to simulate a 3-stages countercurrent liq-liq extraction. The partition coefficients of the different analytes were estimated with different techniques experimentally and in silico. HPLC and slice-selective NMR were exploited to evaluate the partition of trimetozine between the organic and the aqueous phase. Aspen sensitivity analysis was also conducted on the optimised NRTL model to assess the effect of certain process variable on the yield of extract.

\section{AUTHOR INFORMATION}

\section{Corresponding Author}

* (Word Style "FA Corresponding Author Footnote"). Give contact information for the author(s) to whom correspondence should be addressed.

\section{Present Addresses}

$\dagger$ If an author's address is different than the one given in the affiliation line, this information may be included here.

\section{Author Contributions}

The manuscript was written through contributions of all authors. / All authors have given approval to the final version of the manuscript. / \$These authors contributed equally. (match statement to author names with a symbol)

\section{Funding Sources}

Any funds used to support the research of the manuscript should be placed here (per journal style).

Notes

Any additional relevant notes should be placed here.

\section{ACKNOWLEDGMENT}

(Word Style "TD_Acknowledgments"). Generally, the last paragraph of the paper is the place to acknowledge people (dedications), places, and financing (you may state grant numbers and sponsors here). Follow the journal's guidelines on what to include in the Acknowledgement section.

\section{ABBREVIATIONS}

CCR2, CC chemokine receptor 2; CCL2, CC chemokine ligand 2; CCR5, CC chemokine receptor 5; TLC, thin layer chromatography.

\section{REFERENCES}

Albright's chemical engineering handbook. Choice Rev. Online (2013). doi:10.5860/choice.46-4467

2. Zhang, J. \& Hu, B. Liquid-Liquid Extraction (LLE). in Separation and Purification Technologies in Biorefineries 61-78 (John Wiley \& Sons, Ltd, 2013). doi:10.1002/9781118493441.ch3

3. Wei, W. et al. Selective recovery of $\mathrm{Au}(\mathrm{III}), \mathrm{Pt}(\mathrm{IV})$, and $\mathrm{Pd}(\mathrm{II})$ from aqueous solutions by liquid-liquid extraction using ionic liquid Aliquat336. J. Mol. Liq. (2016). doi:10.1016/j.molliq.2016.01.016

4. Jiao, T. et al. The new liquid-liquid extraction method for separation of phenolic compounds from coal tar. Chem. Eng. J. (2015) doi:10.1016/j.cej.2014.12.071
Sas, O. G., Domínguez, I., González, B. \& Domínguez, Á. Liquid-liquid extraction of phenolic compounds from water using ionic liquids: Literature review and new experimental data using [C2mim]FSI. $J$. Environ. Manage. (2018). doi:10.1016/j.jenvman.2018.09.042

Maruyama, T., Ishizu, N., Eguchi, Y., Hosogi, T. \& Goto, M. Liquid-liquid extraction of enzymatically synthesized functional RNA oligonucleotides using reverse micelles with a DNA-surfactant. Chem. Commun. (2016). doi:10.1039/c6cc06985a

Rezaee, M., Yamini, Y. \& Faraji, M. Evolution of dispersive liquid-liquid microextraction method. Journal of Chromatography A (2010). doi:10.1016/j.chroma.2009.11.088

Silvestre, C. I. C., Santos, J. L. M., Lima, J. L. F. C. \& Zagatto, E. A. G. Liquid-liquid extraction in flow analysis: A critical review. Anal. Chim. Acta 652, 54-65 (2009).

Güell, R., Fontàs, C., Salvadó, V. \& Anticó, E. Modelling of liquid-liquid extraction and liquid membrane separation of arsenic species in environmental matrices. Sep. Purif. Technol. 72, 319-325 (2010).

Alimuddin, M. et al. Determination of $\log \mathrm{D}$ via automated microfluidic liquid-liquid extraction. J. Med. Chem. 51, 5140-5142 (2008).

Chouai, a., Cabassud, M., Le Lann, M. V., Gourdon, C. \& Casamatta, G. Use of neural networks for liquid-liquid extraction column modelling: an experimental study. Chem. Eng. Process. Process Intensif. 39, 171-180 (2000).

Binous, H. Liquid-liquid equilibrium and extraction using Mathematica?? Comput. Educ. J. 16, 78-81 (2006).

Homrich, P. O. B., Dias, L. G., Mariutti, L. R. B., Bragagnolo, N. \& Ceriani, R. Liquid-liquid equilibria and density data for pseudoternary systems of refined soybean oil + (hexanal, or heptanal, or butyric acid, or valeric acid, or caproic acid, or caprylic acid)+dimethyl sulfoxide at 298.15 K. J. Chem. Thermodyn. (2019). doi:10.1016/j.jct.2018.10.030

Gouveia, A. S. L., Oliveira, F. S., Kurnia, K. A. \& Marrucho, I. M. Deep Eutectic Solvents as Azeotrope Breakers: Liquid-Liquid Extraction and COSMO-RS Prediction. ACS Sustain. Chem. Eng. (2016). doi:10.1021/acssuschemeng.6b01542

Birajdar, S. D., Padmanabhan, S. \& Rajagopalan, S. Rapid solvent screening using thermodynamic models for recovery of 2,3-butanediol from fermentation by liquid-liquid extraction. J. Chem. Eng. Data 59, 2456-2463 (2014).

Shah, M. R. \& Yadav, G. D. Prediction of liquid-liquid equilibria of (aromatic+aliphatic+ionic liquid) systems using the Cosmo-SAC model. $J$. Chem. Thermodyn. 49, 62-69 (2012).

Maurer, G. Modeling the liquid-liquid equilibrium for the recovery of carboxylic acids from aqueous solutions. Fluid Phase Equilib. 241, 86-95 (2006).

White, T. D. et al. Development of a continuous Schotten-Baumann route to an acyl sulfonamide. Org. Process Res. Dev. 16, 939-957 (2012).

Kawahara, K. \& Ofuji, T. Simultaneous determination of glucuronides of trimetozine in human urine by gas chromatography. J. Chromatogr. B Biomed. Sci. Appl. (1982). doi:10.1016/S0378-4347(00)81858-7

Vanderveen, J. R. et al. Non-random two-liquid modelling of switchablehydrophilicity solvent systems: N,N-Dimethylcyclohexanamine, water, and toluene. Fluid Phase Equilib. (2016). doi:10.1016/j.fluid.2015.09.032

Thomsen, K. Modeling electrolyte solutions with the extended universa quasichemical (UNIQUAC) model. Pure Appl. Chem. (2005). doi:10.1351/pac200577030531

Do Carmo, F. R., Evangelista, N. S., De Santiago-Aguiar, R. S., Fernandes, F. A. N. \& De Sant'Ana, H. B. Evaluation of optimal activity coefficient models for modeling and simulation of liquid-liquid equilibrium of biodiesel + glycerol + alcohol systems. Fuel (2014). doi:10.1016/j.fuel.2014.01.108

Yang, X. D. et al. Silica gel-mediated amide bond formation: An environmentally benign method for liquid-phase synthesis and cytotoxic activities of amides. J. Comb. Chem. (2010). doi:10.1021/cc900135f

Khan, K. M. et al. Leishmanicidal potential of N-substituted morpholine derivatives: Synthesis and structure-activity relationships. Nat. Prod. Res. 23, 479-484 (2009) 
